\title{
BIOLOGICAL AND GENETIC CHARACTERISTICS OF TWO TRICHINELLA ISOLATES in ChINA; COMPARISON WITH EUROPEAN SPECIES
}

\author{
LIU M.Y.*, ZHU X.P.***, XU K.C.*, LU Q.* \& BOIREAU P.**
}

\section{Summary :}

The most recent taxonomic revision in Trichinella genus included 10 taxa. Trichinella spiralis (Ts) is a thoroughly studied species but most of the isolates came from the Europe or American continents. Few information is available from China about the Trichinella isolates and their diversity. In this report two Chinese isolates were characterized and compared with European strains. The in vitro release of newborn larvae (NBL) was determined for the two species. NBL is observed in supernatant of cell culture after adults purification on day 4 post infection (pi) with Ts, and on day 5 pi with Trichinella nativa (Tna). A new parameter was thus proposed to characterize Trichinella strains. Restriction fragment length polymorphism (RFLP) of genomic DNA and random amplified polymorphic CDNA (RAPD) were used to define genetic variability among different isolates. Species specific pattern could be obtained with RAPD but it was far more difficult to get geographical markers for Trichinella using these methods. A low genetic variability in Trichinella species (i.e a strong "clonality") is suggested.

KEY WORDS : China, cDNA, PCR, sequencing, Trichinella.

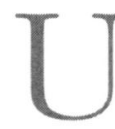
p to now, the genus Trichinella has been partitioned into seven species including T. spiralis (Ts), T. nativa (Tna), T. britovi (Tb), T. pseudospiralis (Tps), T. murrelli (Tm), T. nelsoni (Tn), T. papuae (Tp) (Pozio et al., 1999), and three unclassified gene pools, T6, T8 and T9. Each species was characterized by biological, epidemiological, biochemical, and molecular properties in the genus Trichinella (Pozio et al., 1992; La Rosa et al., 1992, Pozio \& La Rosa, 2000). Genetic variations were found in various geographic isolates of the same species. Zarlenga et al. (1996) analyzed the ribosomal DNAs of three isolates of Tps from a raccoon dog in Russia, a black vulture in North America, and a quoll in Australia; differences were observed in the PCR amplification patterns and in the nucleo-

\footnotetext{
* The Quartermaster University of PLA, 175 Xian Road, Changchun 130062, P. R. China.

** UMR INRA-AFSSA-ENVA, Biologie Moléculaire et Immunologie Parasitaires et Fongiques, 22, rue Pierre Curie, 94703, MaisonsAlfort, France.

*** Capital University of Medical Sciences, Beijing 100054, P. R. China Correspondence: Liu M.Y., The Quartermaster University, 175 Xian Road, Changchun 130062, P.R. China.Tel.: +86 4317998047 Fax: +86 431 7983442. - E-mail: liumy36@yahoo.com
}

tidic sequence of ribosomal genes. Minchella et al. (1994) analyzed the genomic DNA variation of Tm isolates coming from various hosts (opossum, coyotes, raccoons and red foxes) and found a variation in the polymorphic repetitive DNA profiles. La Rosa \& Pozio (2000) performed a molecular investigation of three African isolates of $\mathrm{Tn}$, and the species specific probe (pT7.3) hybridized Kenya and Tanzania isolates but failed to recognize South African isolates.

Ts is characterized by its high prolificity and infectivity in human but few information exist on the Ts Chinese strains. The present study analyzed some biological and genetic characteristics of two Chinese Trichinella isolates. Comparison with European strains was performed using restriction fragment length polymorphism (RFLP) of genomic DNA and random amplified polymorphic cDNA (RAPD). An easy to use new parameter was defined to identify strain with high prolificity (Ts).

\section{MATERIALS AND METHODS}

\section{PARASITE}

The following isolates were maintained in OF1 female mice by serial passages: Chinese Ts ISS534 (C1), Chinese Tna ISS531 (C2), European Tna ISS10 (E2) and two European Ts ISS406 (E3) and ISS3 (E1). Muscle larvae (ML) were collected by artificial digestion 35 days post infection (pi) as described by Gamble et al. (1983). Adult worms were purified from the intestinal tract on days 3 ( $\operatorname{Ad} 3$ ), four, five and six post infection (pi) as previously described (Vayssier et al.,1999).

\section{THE INITIAL TIME}

OF NEW BORN LARVAE (NBL) RELEASE;

DETERMINATION OF IN VITRO ADULT WORM FECUNDITY

Four groups of mice were infected with four isolates (C1, C2, E2 and E3) respectively. Each group was constituted of five mice and each mouse was infected per os with 2,000 ML. One mouse of each isolate was 
killed on days 3, 4, 5 and 6 pi. A total 96 adults of each isolate was selected every day and cultured individually in 96-microwell culture plates in RPMI 1640 (Gibco) containing $1 \%$ pyruvate, $15 \%$ foetal calf serum, 100 i.u./mL penicilline and $100 \mu \mathrm{g} / \mathrm{mL}$ streptomycine, $1 \% \mathrm{~L}$-glutamine for three days, at $37^{\circ} \mathrm{C}$ in $5 \%$ $\mathrm{CO}_{2}$ atmosphere. NBL released were checked by microscopy and a quantification was performed in each well every day.

\section{GENOMIC DNAS ANALYSIS BY RFLP}

Genomic DNA of each isolates (C1, C2, E1 and E2) was extracted as described by Klassen \& Thiessen (1986). Trichinella DNA $(1 \mu \mathrm{g})$ was digested with endonucleases EcoRI, XbaI, DraI using the buffer and temperature condition recommended by the manufacturer (Pharmacia). Digested DNA was analyzed after electrophoresis on a $1.2 \%(\mathrm{w} / \mathrm{v})$ agarose gel which was stained with $1 \mu \mathrm{g} / \mathrm{mL}$ ethidium bromide bath and photographed under UV transillumination.

\section{CDNAS ANALYSIS BY RANDOM AMPLIFIED POLYMORPHIC SEQUENCE (RAPD)}

- cDNA libraries construction: ML was collected for each isolates (C1, C2, E2 and E3). Pooled adults/new born larvae (Ad/NBL) were collected with C1, C2 and E3 isolates on day 5 pi. Total RNA of ML or Ad/NBL were extracted according to the method described by Chomczynski et al. (1987). $\lambda$ ZAP II cDNA libraries (Short et al., 1988) were established for each preparation as described (Vayssier et al., 1999). Plasmids of individual cDNA libraries were excised from the phage vector under in vivo condition following the protocol of the manufacturer (Stratagene).

- cDNA amplification: 80 primers divided in four groups (OPA 20, OPB 20, OPC 20, OPD 20) were used in the RAPD analysis. Amplification reactions were performed in $25 \mu \mathrm{l}$ volumes containing $10 \mathrm{mM}$ Tris-HCl, pH 8.3; $50 \mathrm{mM} \mathrm{KCl;} 25 \mathrm{mM} \mathrm{MgCl}_{2} ; 0.01 \%$ (w/vol) gelatin; $100 \mathrm{mM}$ each dATP, dCTP, dGTP and dTTP (Pharmacia); $4 \mu \mathrm{M}$ primer (one or two or three primers); 30 ng cDNA with plasmid; and 2.5 units of Taq polymerase. The amplification was programmed for 45 cycles of one minute at $94^{\circ} \mathrm{C}$, one minute at $36^{\circ} \mathrm{C}$ and two minutes at $72^{\circ} \mathrm{C}$. Amplification products were visualized after electrophoresis on $1.4 \%$ agarose gels.

\section{Cloning and Sequencing of DNA Amplicon}

DNA band was purified from agarose gel using QUIAEX kit (Quiagen) and was ligated to pT-adv vector before transformation of TOP $10 \mathrm{~F} \mathrm{E}$. coli. The insert was fully sequenced on both strands four times by Genome Express.
DNA amplified fragment was radiolabelled and used to screen the Ad/NBL Ts cDNA library by plaque hybridisation. Positive clones were selected and plaques purified two times by hybridisation. pBluescript plasmids containing cDNA were derived from the $\lambda$ ZAP phages using the in vivo excision procedure described by Short et al. (1988). Several independent clones (4) were sequenced on both strands by Genome Express. Nucleotide and amino acid sequence analysis were carried out using OMIGA (Intelligenics, CA, Version 2).

\section{RESULTS}

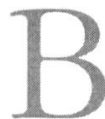
iological properties of Chinese and European strains were analyzed using two parameters: the initial time of NBL release by female worm and the prolificity. Chinese and European Ts isolates expelled NBL as early as day 4 pi whereas Tna did it on day 5 for both isolates. A delay in the NBL release was also observed with two European Tb strains (unpublished data). The prolificity of the female worm is reported in Table I. Ts produced always more NBL and earlier than Tna and whatever the geographic isolate the prolificity is similar for a same species. Standard deviation was important on day 4 as some female (an average of $20 \%$ ) did not expelled NBL.

In order to characterize the genome of these isolates, restriction profiles of genomic DNA using various restriction enzymes was performed (Fig. 1). The profiles between $\mathrm{C} 1$ and $\mathrm{E} 1$, and between $\mathrm{C} 2$ and $\mathrm{E} 2$, were highly similar whatever the restriction enzymes used but significant differences were identified between the two groups (Fig. 1). C1 and E1 had a unique EcoRI band at $1.82 \mathrm{~kb}$, a Dral band at $0.89 \mathrm{~kb}$ and a Xbal band at $0.72 \mathrm{~kb}$ which were absent in C2 and E2 isolates.

As no geographic maker could be selected with RFLP analysis, a more sensitive method was used to iden-

\begin{tabular}{lcccc}
\hline & & $\begin{array}{c}\text { NBL/female } \\
\text { day } \mathbf{4} \mathbf{~ p i}\end{array}$ & $\begin{array}{c}\text { NBL/female } \\
\text { day } \mathbf{5 ~ p i}\end{array}$ & $\begin{array}{c}\text { NBL/female } \\
\text { day 6 pi }\end{array}$ \\
\hline $\begin{array}{l}\text { Chinese } \\
\text { isolates }\end{array}$ & $T s$ & $5.6 \pm 4.61$ & $53.7 \pm 6.8$ & $52.4=3.6$ \\
$\begin{array}{l}\text { European } \\
\text { isolates }\end{array}$ & $T S$ & $4.0 \pm 2.3$ & $50.2 \pm 7.1$ & $51.3=5.7$ \\
$\begin{array}{l}\text { Chinese } \\
\text { isolates }\end{array}$ & Tha & 0 & $29.5 \pm 5.3$ & $30.1=2.8$ \\
$\begin{array}{l}\text { European } \\
\text { isolates }\end{array}$ & Tna & 0 & $30.8 \pm 6.2$ & $30.5=5.9$ \\
\hline
\end{tabular}

Table I. - Prolificity of Trichinella females in vitro. A comparison between Ts and Tna purified on days 4,5 and 6 pi. The quantification was done three days after purification of Ad. Ad purified on day 3 did not expelled NBL. 


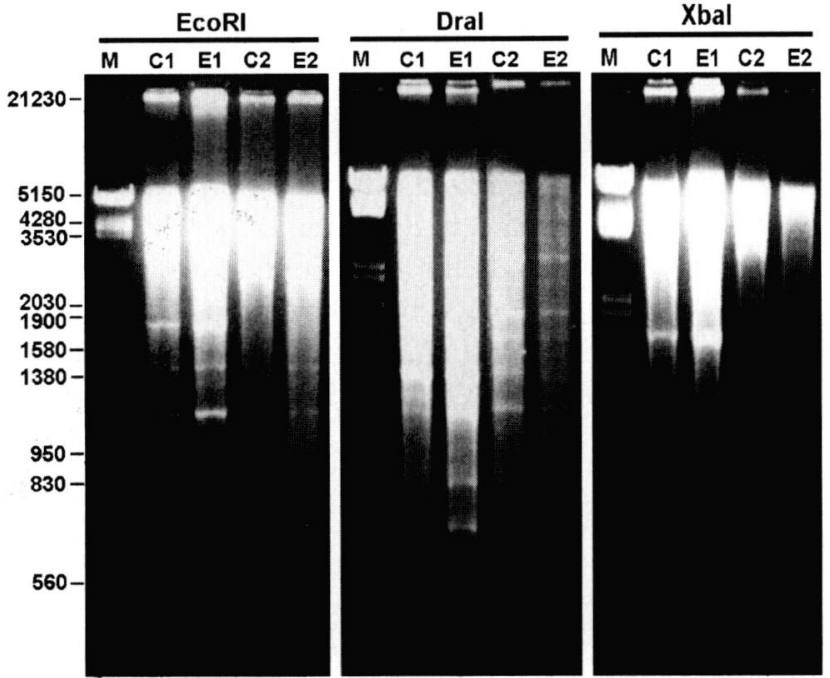

Fig. 1. - Genomic DNAs digested by EcoRI, DraI, Xbal. Lane M: Molecular weight marker. C1: Chinese Ts. E1: European Ts. C2: Chinese Tna. E2: European Tna. The fluorescence smear in each lane represents randomly cleaved non-repetitive DNA sequence; superimposed bands are visualized in each lane and represent repetitive sequences. Fluorescence intensity in each band depends on the copy number of the multi sequence family as well as the length of the repeat unit.
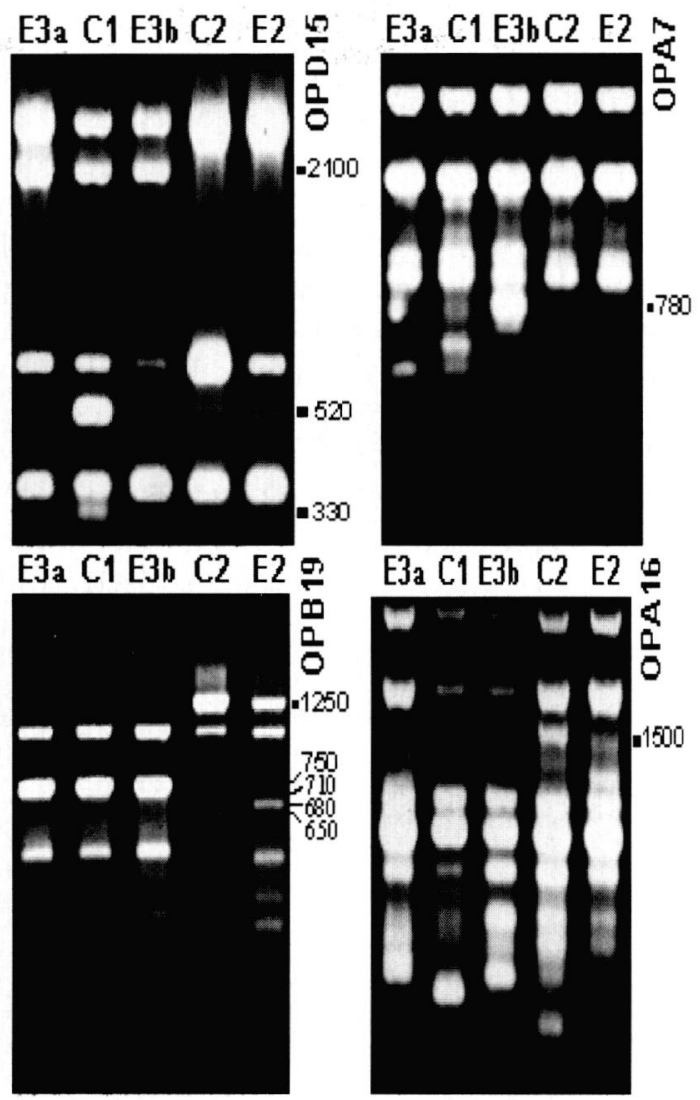

Fig. 2. - Random PCR with cDNA plasmidic libraries of Trichinella. E3a: Ad/NBL cDNA library of E3, C1: Ad/NBL cDNA library of C1, E3b: ML cDNA library of E3, C2: Ad/NBL cDNA library of C2, E4: ML cDNA library of E4. The primer used in each experiment and molecular weight markers are indicated on the right part of each gel. tify specific nucleotidic sequence. For that purpose plasmidic CDNA libraries of $\mathrm{C} 1, \mathrm{C} 2, \mathrm{E} 2$ and $\mathrm{E} 3$ isolates were analyzed by RAPD using 80 primers under various combinations (250). Most of the amplified profiles were similar for the four isolates indicating a high stability of expressed genes. Reproducible differences were observed in the amplifications with primer OPD15 (CATCCGTGCT), OPA7 (GAAACGGGTG), OPB19 (ACCCCCGAAG), OPA16 (AGCCAGCGAA) (Fig. 2), and allowed to separate Ts group from Tna one whatever the antigenic stage (ML or Adult/NBL) or the geographic isolate used (Fig. 2). Some minor differences could be obtained with primer OPD15 between the Chinese and European Ts isolates particularly one band of $520 \mathrm{bp}$ appeared with less intensity in one isolate. A bright DNA band of 2,100 bp appeared highly specific of Ts group and was absent with Tna group and primer OPD15. This DNA band was purified and fully sequenced after cloning for both strains. The primer used in the amplification could be recognized on one extremity. Two third of the sequence belong to pBluscript plasmid and the last third (542 bp) was specific of Trichinella species. Two bases changes were found in these 542 bp sequence (Fig. 3) between Chinese Ts and French Ts isolates. This Ts DNA insert was used to screen Ts Ad/NBL cDNA library (Chinese isolate). Several independent clones were selected and sequenced. The consensus nucleotidic sequence was 1,345 bp long with a unique open reading frame of 942 nucleotides encoding a putative protein of 314 amino acids (aa) with a molecular weight of $35,56 \mathrm{kDa}$. The variation on two bases was confirmed but there was no modification of the deduced primary aa sequence for both isolates. The first modified codon encode a Thr and the second a Leu residue. Comparison of the deduced aa sequence with data base did not revealed any significant homology with known coding sequence. The full length DNA sequence hybridized the eight Trichinella genome by dot blot analysis (data not shown) indicating that the variability of this sequence is limited to base changes among Trichinella genus.

\section{DISCUSSION}

The analysis of biological characteristics is a common method to characterize Trichinella species (Belosevic \& Dick, 1979; Pozio et al., 1992).

The initial time of NBL release and the fecundity index of adult worm after their purification from intestinal tract are two simple and discriminant biological parameters. Ts showed the highest and earliest NBL release by comparison with Tna and $\mathrm{Tb}$ (data not shown). Rossi et al. (1993) performed similar study with five Trichinella species (Ts, Tna, Tne, Tb, Tps), and found 


$$
-\boldsymbol{G}
$$

TCCAATTCTT CTTGTATTTG CTTTATACTT CTTGATAATC TCGTCGTCAT

TTTCCGAAAA AATCCACTCA ATTACAGCCA ATGATTGAAT TATCTGCATC

\section{TGACTGATAG3' 542}

------- $3^{\prime}$

Fig. 3. - Sequence comparison of common DNA band ( $520 \mathrm{bp}$ ) extracted after random PCR with cDNA of C1 and E3a (primer OPB15). The sequence of the primer is identified at the starting of the DNA fragment (italic) for both species. Bases changes are in bold.

the adult worms of all species release NBL on day 6 pi. This discrepancy with our results could reflect the host influence as CD1 female mice was used in Rossi' experiment. NBL stage specific probes were used to hybridize cDNA from Ts adult worm purified on day 3 or 5 (Liu Mingyuan \& P Boireau, unpublished data). Only the cDNA of Ad worm collected five days pi gave a positive result demonstrating the presence of mature NBL. In vitro NBL release index did not show any significant difference between Chinese and European varieties of Trichinella despite the fact that each strain was isolated from various hosts.

Nevertheless the highest fecundity of Ts is confirmed for Chinese isolate as previously described for other Ts strains (Pozio et al., 1992). In the same order, Tna appeared with a lowest prolificity whatever the geographical variety selected.

Informative RFLP pattern were obtained with Chinese and European species, the differences could be clearly revealed between species but were difficult to repro- duce with geographic isolates of the same species. Base changes or deletion of repetitive sequences in the intron have been a good target to distinguish various Trichinella phenotypes, but few studies using the encoding sequences were performed. In the present report, we attempt to select species specific probes using RAPD with CDNA. Four cDNA libraries amplified by various combinations of primers were used to analyze sequence variation among four Trichinella isolates. Species variation could be identified with several primers but only one primer revealed a minor geographic difference. Wu et al. (1998) designed two primer pairs Ts53CA and Ts43CA, based on the cDNA of 53 $\mathrm{kDa}$ and $43 \mathrm{kDa}$ glycoproteins and used the genomic DNA as template to amplify the full length coding regions. The study revealed bases changes either in encoding sequence or in intron. Our result reinforced the interest to use cDNA sequence and PCR in taxonomic studies of Trichinella genus despite the fact that RAPD or directed PCR on repetitive sequence were 
reported to differentiate more easily various Ts isolates (Dick et al., 1992).

The nucleic acid sequence comparison between the two isolates $\mathrm{C} 1(\mathrm{Ts})$ and E3(Ts) with a same amplicon revealed two muted base changes. Some punctual base changes explained the variation in RAPD pattern on CDNA.

The initial time of NBL release is a new biological parameter that can be checked to identify highly prolific Trichinella species (Ts). Random amplification (more than 200) on cDNA libraries proved the high stability of coding sequence for each species in Trichinella genus and confirmed previous results obtained with monoclonal antibodies (Boireau et al., 1997): a strong clonality exist for Trichinella species.

\section{ACKNOWLEDGEMENTS}

W e are grateful to Dr. Edoardo Pozio who provided the reference isolates of Trichinella. This work was supported by PRA 9612 grant (International cooperation grant between China and France) and NSFC grants (National Natural Science Foundation of China). We thank Miss Isabelle Vallee, Mr Thibaud Romand, Mr Li Chengyao and Mr Zheng M.G. for their helps and helpful discussion.

\section{REFERENCES}

Belosevic M. \& Dick T.A. Trichinella spiralis: comparison of stages in host intestine with those of an Arctic Trichinella sp. Experimental Parasitology, 1979, 48, 432-46.

Boireau P., Vayssier M., Fabien J.F., Perret C., Calamel M. \& SOulé C. Antigenic analysis of L1M of Trichinella T1 and T5 using 40 monoclonal antibodies: characterization of eleven antigenic groups and identification of new species markers. Parasitology. 1997, 115, 641-651.

Chomczynski P. \& SACCHI N. Single-step method of RNA isolation by acid guanidium thiocyanate-phenol-chloroform extraction. Analytical Biochemistry, 1987, 162, 156159.

Dick T.A., Lu M.C., Theo D. \& Ma K. The use of polymerase chain reaction to identify porcine isolates of Trichinella. The Journal of Parasitology, 1992, 78, 145-148.

Gamble H.R., Anderson W.R., Graham C.E. \& Murrell K.D. Serodiagnosis of swine trichinosis using an excretorysecretory antigen. Vet. Parasitol., 1983, 13, 349-361.

KLAsSEn G.R. \& Thiessen J.P. Analysis of repetitive sequences in the Trichinella genome: three strain-specific patterns. The Journal of Parasitology, 1986, 72, 772-775.

La Rosa G., Pozio E., Rossi P. \& Murrell K.D. Allozyme analysis of Trichinella isolates from various host species and geographical regions. Journal of Parasitology, 1992, 78, 641-646
LA Rosa G. \& Pozio E. Molecular investigation of African isolates of Trichinella reveals genetic polymorphism in Trichinella nelsoni. International Journal for Parasitology, 2000, 30, 663-667.

Minchella D.J., Eddings A.R. \& NeEl S.T. Genetic, phenotypic, and behavioral variation in North American sylvatic isolates of Trichinella. Journal of Parasitology, 1994, 80, 696-704

Pozio E., La Rosa G., Murrell K.D. \& Lichtenfels J.R. Biological characterization of Trichinella isolates from various host species and geographical regions. Journal of Parasitology, 1992, 78, 647-653.

Pozıo E. \& LA Rosa G. Trichinella murrelli n. sp: etiological agent of sylvatic trichinellosis in temperate areas of North America. Journal of Parasitology, 2000, 86, 134-139.

Pozio E., Owen I.L., La Rosa G., Sacchi L., Rossi P. \& Corona S. Trichinella papuae n. sp. (Nematoda), a new non-encapsulated species from domestic and sylvatic swine of Papua new Guinea. International Journal of Parasitology, 1999, 29, 1825-1839

Rossi P., Ludovisi D., Amati M. \& Pozio E. The intestinal phase of Trichinella species: a comparative study. Proceedings of Eighth International Conference on Trichinellosis, 1993, ISSN 0393-5620, Rome, 185-190.

Short J.M., Fernandez J.M., Sorge J.A. \& Huse W.D. $\lambda$ ZAP: a bacteriophage with in vivo excision properties. Nucleic acids Research, 1988, 16, 7583-7600.

Vayssier M., Le Guerhier F., Fabien J.F., Philippe H., Vallet C., Ortega-Pierres G., Soulé C., Perret C., Liu M.Y., Vega-Lopez M. \& BOIREAU P. Cloning and analysis of a Trichinella britovi gene encoding a cytoplasmic heat shock protein of $72 \mathrm{kDa}$. Parasitology, 1999, 119, 81-93.

Wu Z., Nagano I. \& TaKahashi Y. The detection of Trichinella with polymerase chain reaction (PCR) primers constructed using sequences of random amplified polymorphic DNA (RAPD) or sequences of complementary DNA encoding excretory-secretory (E-S) glycoprotein. Parasitology, 1998, 117, 173-183.

Zarlenga D.S., AsChenbrenner R.A. \& Lichtenfels J.R. Variations in microsatellite sequences provide evidence for population differences and multiple ribosomal gene repeats within Trichinella pseudospiralis. Journal of Parasitology, 1996, 82, 534-538. 